\title{
Basics of scientific and technical writing: Patents
}

\author{
By Morteza Monavarian
}

This article is the second in a three-part series in MRS Bulletin that will focus on writing papers, patents, and proposals.

\section{The basics on patents}

A patent is a form of intellectual property (IP) that gives the right to the inventors to exclude others from making, using, or selling an invention for a certain period of time (usually 20 years). The inventors should publish a public disclosure of the invention in return. For the inventors, however, a patent does not automatically give the right to make, use, or sell an invention. Patents are considered private law, which means if someone violates the patent law and uses the idea for commercial purposes during the term of the patent, the inventor can sue them to enforce the law.

\section{Patentability criteria}

There are three main criteria to ensure an idea is patentable: novelty, usefulness (or utility), and non-obviousness. The first major criteria of patentability is novelty, which means that the idea is not publicly known before the filing date of the patent or before any priority date of the patent. This is to avoid the patenting of prior ideas. According to the second criteria (utility), an invention needs to be useful to ensure its patentability. Utility here means the invention should provide clear benefits and should be capable of use. This may differ with various countries (e.g., European patent law and US patent law have different rules). Non-obviousness, which is a general requirement of most patent laws, means that the invention or the idea of the invention should be sufficiently beyond or above the current state of the art. For example, if a patent is filed on a method with a certain material, one may not be able to patent the same method with another material if these two materials are known to be used interchangeably.

\section{Types of patents}

Different types of patents include utility, design, and plants. Each patent type has its own eligibility requirements and is useful for a certain type of invention. One patent can have more than one suitability. For example, if we need to patent a device and reserve its right for both functionality and design, two separate patents can be filed. Utility applications are the most common and normally cover processes, materials, and devices with functions that are new and useful. Design applications normally cover the shape and configuration of an object (e.g., the exterior shape of a car, cell phone, or laptop). Finally, plant patents are to protect new and distinctive plants.

\section{Applications}

A patent application is submitted to a patent office with detailed aspects of the invention described in the specifications along with a set of claims stated in the formal document. Once the specifications are approved, a patent is granted.

A provisional application places an application on file for one year to secure a priority date, but without the complexity and expense of a standard application. After the one-year period, one can file a non-provisional standard patent application, while reserving the priority date of the provisional application. Depending on the outcome of the patent office examination, the patent may be granted. One can also file a continuation application, under certain circumstances, to include materials from an earlier application when the priority year has expired.

A patent filed in the United States is submitted to the United States Patent and Trademark Office (USPTO). The World Intellectual Property Organization (WIPO) is an office for international applications. A US patent (from USPTO) does not guarantee international protection of your IP, but, a world patent can cover several countries.

\section{Patent structures}

A patent application generally consists of (1) a patent summary, (2) patent specifications, (3) list of claims (independent and dependent), (4) drawings and descriptions, (5) references, and (6) signed Proper IP Disclosure and Declaration forms. The patent summary should provide an overview of the idea and what is to be disclosed in the patent. The main body of the patent specifications should provide details of the background, state-of-the-art features (may also include a summary of prior art search results), and descriptions of the invention, drawings, and figures. Independent claims provide an overview of the invention. Dependent claims provide details and variations of the invention. For a utility application, the claims can be either method- or device-based. Method claims are those that describe novel methods presented in the patent, while device claims are for claiming inventive devices; these claims can be separate. Drawings are in black and white, unlike figures in papers, which tend to vary in color. Other textures or 
pattern fills, such as shades, diagonal lines, and dashes, can be used in the schematics/figures/drawings, or each section of the figures can be numbered followed by proper descriptions. Similar to papers, patents also contain a reference section to cite prior art (e.g., patents, papers) and relevant works in the specifications. Proper IP Disclosure and Declaration forms should be submitted by each inventor.

\section{Steps to file a patent}

The figure shows a standard process flow for a patent, from idea to filing to granting. Assuming an idea is developed, the first step is to secure it. One approach is to write it down on a piece of paper, and sign and date it (this will help when you want to claim an earlier priority date in your application), or save an email sent to your co-inventors or to yourself describing the idea.

The second step is to verify whether the idea is patentable; check its novelty,

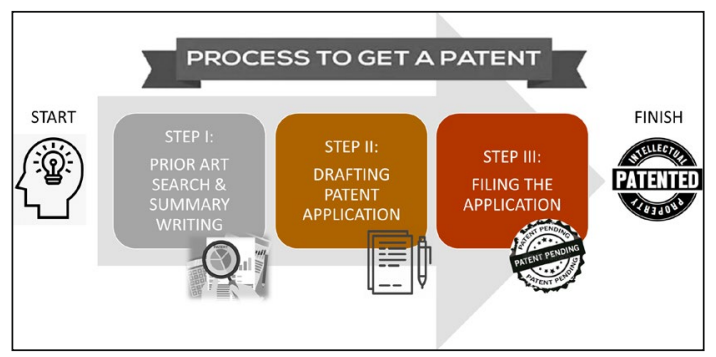

utility, and non-obviousness. Particularly for novelty, perform a prior art search, including previously published patents, papers, or any other relevant documents.

Then, secure a patent type and write a summary document, which describes the field of invention, description of the prior art, invention specifications, details of the idea with figures and any simulation or experimental data, references, and tentative claims (independent and dependent, method, or device claims). The tentative claims will help the patent office to write proper final claims according to your invention. A good patent application requires illustrative drawings with proper descriptions. Most institutes have illustrators to prepare the drawings, but they will need a base figure and several iterations to achieve a decent, comprehensive drawing for the invention.

The specification document, along with any other supporting documents (e.g., relevant paper publications, thesis), should be sent to the patent office at your institution, along with signed IP disclosure forms, including the patent intellectual contribution shares for each inventor. The inventors should also mention the stage of the idea-whether it is at the concept level or if it has been fully/partially reduced to practice. The inventors should also mention whether the idea is developed or fully/partially reduced-to-practice as a result of any governmental or industrial funding source.

The patent office will conduct a patentability check to determine if it is interested in pursuing the patent. It also check the priority date to ensure there is no significant public disclosure (e.g., publications, presentations, reports). A patent may be rejected if it was disclosed to the public before a provisional or non-provisional patent is filed.

For a provisional application during the one-year period, inventors will have time to further reduce the invention to practice. The patent office will also conduct a systematic search for any industry interest in the invention. After the one-year period for provisional applications, depending on the decision of the institute, they will decide whether to re-file or file for a non-provisional application or to abandon the application. After a non-provisional application is filed, USPTO or WIPO examines the application. Upon approval from another novelty and non-obviousness check with the prior art, a patent with the inventive concepts disclosed is granted and will be approved for public disclosure.

\section{To do or not to do, that is the question}

- Do not pursue a patent for every idea. Select those that have clear industrial applications and can be reduced to practice reasonably quick.

- Only spend time on ideas that are worth patenting. Conduct a novelty search first.

- Reduce your invention to practice. Gather any experimental/theoretical data that support the invention.

- Use proper communication tools when discussing your idea with the patent office. Avoid any immature or false claims that could negatively affect your patent application.

- Make illustrative but color-independent drawings. Drawings for patents are typically in black and white. They need proper textures/pattern fills and descriptions to replace the color-coding normally used for standard paper figures.

- Add detailed variations to the idea description, and make drawings that cover all aspects of the invention.

- Improvise. With patents, details and variations are encouraged, as long as they are within the scope of the invention. The patent office will decide whether to split the idea into separate patents.

- Enjoy your idea developments!

Morteza Monavarian, Materials Department, and Solid State Lighting \& Energy Electronics Center, University of California Santa Barbara. 